\title{
Overall summary and some conclusions from the Bremerhaven Workshop
}

\author{
A. R. D. Stebbing ${ }^{1}$, V. Dethlefsen ${ }^{2}$, R. F. Addison ${ }^{3}$, M. Carr ${ }^{1}$, P. M. Chapman ${ }^{4}$, \\ W. P. Cofino ${ }^{5}$, C. Heip ${ }^{6}$, L. Karbe ${ }^{7}$, M. N. Moore ${ }^{8}$, A. D. Vethaak ${ }^{9}$ \\ 'Plymouth Marine Laboratory, Prospect Place, The Hoe, Plymouth, Devon PL1 3DH, United Kingdom \\ ${ }^{2}$ Bundesforschungsanstalt für Fischerei, Institut für Fischereiökologie, Außenstelle Cuxhaven, Deichstraße 12 , \\ W-2190 Cuxhaven, Germany \\ ${ }^{3}$ Bedford Institute of Oceanography, PO Box 1006, Dartmouth, Nova Scotia, Canada B2Y 4A2 \\ ${ }^{4}$ EVS Consultants, 195 Pemberton Ave., North Vancouver, British Columbia, Canada V7P 2 R4 \\ ${ }^{5}$ Free University, Institute for Environmental Studies, De Boelelaan 1115, $1081 \mathrm{HV}$ Amsterdam, The Netherlands \\ ${ }^{6}$ Netherlands Institute of Ecology, Centre for Estuarine and Coastal Ecology, Royal Netherlands Academy of Arts and \\ Science, Vierstraat 28, 4401 EA Yerseke, The Netherlands \\ ${ }^{7}$ Institut für Hydrobiologie und Fischereiwissenschaft, Universität Hamburg, Hydrobiologische Abteilung, Zeiseweg 9, \\ W-2000 Hamburg 50, Germany \\ ${ }^{8}$ Plymouth Marine Laboratory, Citadel Hill, Plymouth, Devon PL1 2PB, United Kingdom \\ ${ }^{9}$ Ministry of Transport and Public Works, Tidal Waters Division, Ecotoxicology Section, PO Box 20907. \\ 2500 EX The Hague, The Netherlands
}

\section{INTRODUCTION}

The Bremerhaven Workshop on Biological Effects of Contaminants in the North Sea continued the series initiated by the IOC Group of Experts on the Effects of Pollution with the Oslo Workshop (Bayne et al. 1988), followed by another extending the approach to tropical seas in the Bermuda Workshop (Addison \& Clarke 1990). The Bremerhaven Workshop has broken new ground in 3 major respects. First, it used a number of vessels to take biological techniques to sea where practicable, or applied them as soon as possible after samples were brought ashore. Second, the workshop deployed the techniques in a context akin to that which might be employed in monitoring programmes on a $200 \mathrm{~km}$ transect, providing a realistic test and basis for comparison. Third, the workshop was of a larger scale and complexity than had been attempted previously, deploying techniques from the molecular to community levels of biological organisation and relating results to a broad range of chemical measurements of tissue, water and sediments.

The primary objective of the workshop was to make an inter-comparison of established and candidate techniques for monitoring programmes. While the techniques were deployed simultaneously on the same gradients, often on the same fish, sediment or water samples, it was not the task of the workshop to attempt to intercalibrate or make any selection using the results. Nevertheless the information presented in the papers, and the data and plots given in the appendices, provide a good basis for a more rigorous comparison and an evaluation of techniques. This is particularly so in the case of EROD and the oyster embryo bioassay, where a number of participants were using similar techniques, providing an extensive database for intercomparison. Some of the techniques that were successfully deployed are identified in the brief review of the results of each group that follows

The planning and execution of the workshop and preparation of the results for publication have spanned 5 yr, during which time significant scientific advances have been made in the field of biological effects techniques and the commitment to deploy them within monitoring programmes. For those who select techniques to incorporate in monitoring programmes there needs to be an awareness that techniques are evolving continually and workshops such as this are necessary to test new techniques, and make comparisons with established ones

\section{CONCLUSIONS FROM DIFFERENT WORKSHOP GROUPS}

$$
\text { Dab - biochemistry }
$$

Indices of MFO activity (EROD and related measurements) in dab liver proved to be reliable indicators of exposure to organic contaminants, despite the timing of the workshop when stress due to reproduction could 
have confounded effects related to contaminants. Fish from the most contaminated onshore stations had highest hepatic MFO activity, and results showed considerable internal consistency. The results further confirm the utility of EROD in dab as a sensitive and informative index of exposure to organic contaminants (chlorinated or polynuclear aromatic hydrocarbons) suitable for use in monitoring programmes. Cholinesterase (AChE and BChE) inhibition, classically induced by organophosphorus and carbamate pesticides, exhibited similar trends, suggesting unidentified contaminants with a similar distribution. Metallothionein induction in dab cannot yet be used as an index of metal exposure, because the relationship between metal exposure and metallothionein induction is complex, varying between tissues and apparently in response to reproductive activity.

\section{Dab - molecular and cellular pathology}

The results from a number of biomarker techniques demonstrate degenerative changes in liver cells without overt expression of disease. These are most marked in fish from the inshore stations, particularly for indices of lysosomal damage (measured by several techniques), together with biomarkers of liver degeneration such as fatty change, presence of ras oncoproteins and preneoplastic foci. In addition, biomarkers of pollutant xenobiotic exposure such as increased endoplasmic reticulum, oxyradical generation and intracellular EROD activity (corroborating the biochemical data) demonstrated clearly that fish showing degeneration had also been exposed.

Dab embryos from the surface plankton showed frequencies of abnormalities that were elevated at the most contaminated sites. A high proportion of such abnormalities have been demonstrated experimentally to be lethal (Cameron pers. comm.). It is unclear what is causing the abnormalities; they may be due to contaminant exposure of the parents on the sea bottom or of eggs in the plankton.

\section{Dab - gross pathology and histopathology}

The prevalence of epidermal hyperplasia/papillomas decreased with distance offshore. Their aetiology remains uncertain and further work is necessary to establish how useful they may be as pollution indicators. While there is much evidence that liver neoplasia in other flatfish species is chemically induced, further evidence is needed to establish this link in dab Nevertheless neoplasia in North Sea dab could well be an indicator of exposure to carcinogenic compounds.
One significant concern with respect to the use of disease frequency for pollution monitoring is the extent to which frequencies and contaminant concentrations in the benthic sediments on which they rest and feed are geographically correlated, when the migratory range of North Sea dab (Rijnsdorp et al. 1992) and the delays between induction and full expression of disease may be many months. The implication is that contaminant concentrations and their biological effect will correlate more closely with rapidly induced lower order indices.

\section{Water quality bioassays}

A range of techniques were deployed at sea, and while they varied considerably in sensitivity, bioassays apparently responded to the 2 water masses in the German Bight (Becker et al. 1992), differentiating the continental coastal water from the offshore water, as Wilson \& Armstrong (1961) did in the English Channel. The ability to differentiate naturally occurring water masses in this way implies that sensitivity of bioassay techniques is adequate to detect significant contamination. This was borne out by responses to contaminated nearshore subsurface water samples and to sea surface microlayer samples. The various techniques showed considerable coherence with each other and in relation to the contamination gradients, generally indicating improved water at the more offshore stations, with the most marked biological effects to samples from the benthic and sea surface interfaces.

\section{Benthos - community structure}

Clear trends in macro- and meiofauna community structure along the German Bight transect appear most closely related to changes in sediment granulometry, water depth and salinity, with particle size the most important factor. However, zinc and/or mercury may also be significant correlates, especially for the copepod species. Marked variations in partitioning of contaminants with the different sediment size fractions may also be important in that the fine fraction $(<63 \mu \mathrm{m})$ had a higher organic carbon content with higher concentrations of associated contaminants.

The capping of drilling site sediments with a layer (several $\mathrm{cm}$ ) of clean well-mixed sediments (Rumohr \& Schomann 1992) in the 2 mo before the workshop resulted in remarkable homogeneity in the meiofauna, while the macrofauna community inhabiting the underlying sediments contaminated by drilling muds reflected the gradient. These findings have important implications for the use of benthic community compo- 
nents for monitoring contaminated sediments, particularly where sediments are mobile and contamination likely to be stratified. Where contaminant stratification is so marked between adjacent layers, sampling for chemical analysis and sediment bioassays needs to be with foreknowledge. Unfortunately the workshop REMOTS survey results, which demonstrated stratification between contaminated and uncontaminated sediments, were not available beforehand.

\section{Benthos - sediment bioassays}

While the sediments tested were not toxic enough to provide an adequate trial of the 11 tests used, a clear recommendation for the infaunal amphipod survival and 48 h oyster embryo larval development techniques is made by the group involved. It should be added that those sediment bioassays that depend on survivorship alone may not be as sensitive as those that utilise sublethal indices of effect. There is a need to incorporate more appropriate indices of effect than lethality, in particular reproductive success.

Many of the participants conducted sediment bioassays in their own laboratories in the Netherlands, the United Kingdom, Canada and the United States. Some sediments were in storage or transit for up to $3 \mathrm{wk}$. This emphasised the need to establish protocols for minimising chemical change in sediments prior to bioassay tests.

Changes in benthic community structure observed during the workshop related primarily to variations in sediment granulometry and it is to be expected that organisms in laboratory sediment bioassays will also be stressed by sub-optimal granulometry for each species. Nevertheless it should be possible to account for this and other factors unrelated to contamination by appropriate experimental design (e.g. reference sediments) or methods for data analysis.

\section{Chemistry}

A major input to the workshop was provided by chemists in 9 laboratories resulting in a comprehensive database for relevant contaminants in tissues, water and sediments. Not only do the analyses help to interpret the biological data, but in addition pose significant questions concerning the behaviour of contaminants in the North Sea. All the chemical data are given in Appendix 1. The chemical programme, though well conceived, was poorly executed due to a failure to appoint 2 chemists in advance of the workshop, who it was intended would assist with sampling and the preparation and curation of samples. Any successor to this workshop should seek the collaboration of chemists at the outset to ensure their active participation at every stage.

\section{Statistics}

The statistical input suffered from similar problems to the chemistry, more specifically the involvement of the statistics co-ordinator should have occurred earlier, and following the workshop a greater input to data analysis was required than was available. In particular the sediment sampling became confused with difficulties in differentiating replicates from pseudo-replicates, due to the involvement of 3 vessels and 2 types of grabs (Van Veen and boxcore), with variation in the methods used to subsample sediments.

The presentation of statistical data has been made as consistent as possible. All data have been put into appendices. Statistical problems arising in some of the papers have been addressed, those that remain are the responsibility of the authors. For example some authors have selected a 'reference' station on the German Bight transect and their use of it may influence the form of the data upon which they have based their interpretation. Another example concerns the inadmissible use of variables as replicates which may influence the form of the data upon which they based their interpretation.

\section{SPECIFIC AREAS OF INTEREST}

In the introduction to this volume (Stebbing \& Dethlefsen 1992), 3 areas of particular interest were highlighted because they helped determine the direction that the workshop took from an early stage. Each is now re-examined.

\section{Indices of health and disease in dab Limanda limanda}

The workshop provided a simultaneous test of a wide range of techniques to measure toxic stress and disease in dab, involving more effort than any other aspect of the workshop. One objective was to obtain a more integrated understanding of the relationship between biochemical, molecular and cellular measurements, which may be used as indices of incipient disease, in relation to overtly expressed disease. In attempting to integrate understanding spanning these levels of organisation, we now have a hypothetical sequence (Moore 1992) incorporating a number of the biochemical, molecular and cellular effects of toxico- 
logically induced degenerative change in the liver likely to precede their overt expression as disease, e.g. liver neoplasia. Thus it may be expected that lower order responses, closer to the mechanistic point of disease induction, may be used to indicate incipient disease. Such techniques may then perhaps be incorporated in monitoring programmes with better understanding of why they should be used, and what they mean with respect to the health of the population.

\section{Water quality bioassays and sea surface microlayer}

Water quality bioassays performed at sea confirmed the overall trend of depressed water quality at the most inshore stations in the plumes of the Rivers Elbe and Weser. Significant responses were found to samples from the sea surtace microlayer and elutriates of sediments from superficial benthic sediments. All the more marked effects detected by the bioassay and other techniques were in relation to the accumulation of contaminants at the sea surlace or benthic interfaces.

While it has been recognised for some time that contaminants accumulate at the microlayer to concentrations many times greater than those in the immediate subsurface, the workshop demonstrated for the first time that the overall effect is to create a layer that may be toxic to those organisms exposed to it. Chemical analysis of microlayer samples showed that significant groups of contaminants imetals $-\mathrm{Cu}^{2+}, \mathrm{Pb}^{2+}$; organotins - TBT) may occur at elevated concentrations in offshore samples. Concentrations of TBT exceeded the UK Environmental Quality Standard (EQS) of $5 \mathrm{ng} \mathrm{l}^{-1}$. The results pose questions regarding the flux of contaminants and the extent to which their accumulation in the microlayer relates to atmospheric deposition, to inputs at the sea surface and to contaminants that rise through the water columns. While the sea surface is a biologically active interface, with numerous species as transient (seasonal, diurnal) members of the neuston, the extent to which they are exposed to the microlayer is unclear. It is known that the meroplanktonic component of the neuston includes the eggs and larvae of invertebrate and fish species, and the elevated frequencies of abnormalities in dab embryos occurring in the surface plankton (Cameron \& Berg 1992).

\section{Triad}

The Triad method of assessing sediment quality depends on an integration of sediment toxicity testing, chemical analysis and benthic community structure. Using the Triad in a burden of evidence approach, sediments nearest the Elbe are moderately polluted. It is evident that all indices of sediment contamination and biological effects should be taken into consideration. In the case of the 2 gradients investigated here, this method of integrating different kinds of data provided no greater insight than other methods.

\section{RESULTS OPENING UP NEW POSSIBILITIES}

\section{Cryopreservation of invertebrate larvae}

The most widely used bioassay in the marine field is that using oyster embryos, and more scientists applied the technique during this workshop than ever before. The utility of the technique is limited by the seasonal reproductive cycle of the adults, so the potential for cryopreserved gametes is considerable in freeing the technique frum seasonal constraints. While there are no problems in freezing sperm, ova have proved more intractable. Nevertheless, within the workshop cryopreserved larvae were used in water quality bioassays at sea for the first time, and in experiments using larval growth and survival they were apparently at least as sensitive as the embryo bioassay. Considerable work is required to establish concentration/response relationships for a comprehensive intercomparison, although cryopreservation clearly enhances the potential of such bioassay techniques.

\section{Abnormalities in fish embryos}

Surveys of fish embryos in the sea surface layers were conducted and subsequently revealed frequencies of abnormalities in a significant proportion of the plankton. Experimental work has established that a high proportion of those larvae designated 'abnormal' do not survive (Cameron pers. comm.), so the elevated frequencies in coastal waters may affect recruitment. It appears that the abnormalities have only come to light using new techniques developed by Cameron \& Berg (1992) for looking at freshly caught embryos, because such abnormalities are obscured by the opacity of preserved material. Since the workshop the scale of fish larval surveys using this technique has been widened to include the whole southern and central North Sea and has confirmed the pattern observed within the workshop of high abnormality frequencies in nearshore waters. Work is now proceeding to identify the likely causes, exploring possible classes of organic contaminants using biochemical indices, and whether the abnormalities result from exposure of the embryos to microlayer contamination or to exposure of the parent before spawning. 


\section{Extraction and preconcentration of contaminants for bioassay}

One problem in deploying water quality bioassays is the difficulty of achieving sensitivity in relatively short term experiments. This problem can now be circumvented by extracting organic contaminants from large volumes of sea water using liquid/solid phase extraction (XAD ion exchange resin) and then conducting bioassays or toxicity tests on the elutriate. Bioassays of contaminants concentrated in this way by a factor of 600 from the water column clearly demonstrated the relatively higher toxicity of more inshore samples (Bening et al. 1992). The selectivity of the ion exchange resin demonstrated that the gradient was due to organic microcontaminants, rather than metals for example. The technique has considerable potential in freeing bioassay techniques of the requirement to achieve such great sensitivity, while introducing the ability to identify the class of contaminant responsible for a detected effect. However, greater caution is also required in interpreting the significance of bioassay results that employ extraction and preconcentration procedures.

\section{COMPARISON OF RESULTS FROM THE TWO POLLUTION GRADIENTS}

\section{German Bight transect}

Overall the biological responses in dab Limanda limanda indicate greater stress in those collected at the more inshore stations within the plumes of the Rivers Elbe and Weser, and were progressively less stressed with distance offshore. There was substantial coherence between many of the biochemical (MFO activity, cholinesterase), molecular and cellular (lysosomal damage, fatty change, abundance of ER) indices of stress in dab liver tissues, which related well with the decline in the concentrations of many of the contaminants in their livers and to a lesser extent to the contamination of benthic sediments on which the fish rest and feed.

Similarly, frequencies of abnormalities in dab em bryos caught in the surface plankton are highest from the inshore stations which may be induced as a result of exposure of the parents to contaminants on the bottom. There is evidence from other species that parental condition may determine the viability of embryos, although exposure of embryos to the sea surface microlayer remains a possibility. Certainly the trend of decreasing contamination offshore was reflected in the results of bioassays using microalgal population growth that respond primarily to nutrient concentrations.
Contamination of the most inshore stations was detected by both the sediment elutriate bioassays and the whole sediment bioassays; the former appeared slightly more sensitive, but direct comparison is not possible because the sediment samples were not the same. Significant changes in benthic community structure (macro- and meiofauna) along the gradient correlated primarily with sediment granulometry rather than contaminant concentrations, although zinc and/or mercury appear to be important for the copepods.

\section{Drilling site transect}

It only became apparent afterwards, when REMOTS data became available, that storms which preceded the workshop (January and February 1990) had covered the drilling site and surrounding area with several centimetres of clean sediment, capping the sediments contaminated with drilling mud. This event was a key factor for the limited set of biological results from the drilling site transect. Biochemical indices in dab Limanda limanda indicated the site was uncontaminated. Sediment samples for bioassay probably included both contaminated and freshly deposited clean sediment from grab samples, but significant responses were only detected in those stations within $250 \mathrm{~m}$ of the drilling site itself. Most informative were the benthic community analyses. The meiofauna inhabiting the uncontaminated and recently deposited sediment showed a remarkable homogeneity, with extraordinarily uniform community structure. This is presumably due not only to the fact that the sediment was uncontaminated, but had also been recently well mixed by the storms that deposited it. It appears that the macrofauna, more deeply embedded in the sediment, had survived the storms and the deposition of clean sand. While the community showed some signs of recovery when data were compared with those of Daan et al. (1990), they still reflected the earlier gradient of effect, 3 yr after drilling had finished.

\section{The Dogger Bank and central North Sea}

While the dominant trends were of decreasing contamination and biological effects with increasing distance offshore, effects were also detected at the most offshore station (Stn 9) over the eastern edge of the Dogger Bank. The responses were slight compared with the overall trend along the transect, but their occurrence, detected by a number of biochemical, molecular and cellular indices in dab, suggests such effects were not aberrant results. Furthermore their 
relation to the concentrations of some contaminants in the sediment fine fraction $(63 \mu \mathrm{m})$ indicates that the questions raised should be investigated further.

It has been recognised for some time that the concentrations of certain contaminants $(\mathrm{Pb})$ in organic-rich fine fraction (see Fig. 14a of Ernst et al. 1988) occur at significantly higher concentrations in the area of the Dogger Bank than in surrounding waters (Sündermann \& Degens 1989). The workshop chemical data indicate that other metals $(\mathrm{Hg}, \mathrm{Cd}, \mathrm{As})$ behave similarly (Appendix 1). The concentrations involved are low in relation to the toxicity and are not likely to have contributed to the observed effects; what is important is that transport mechanisms exist by which contaminants may be reconcentrated offshore in benthic sediments. The particular metals involved suggest their introduction via the atmosphere (Dr A. W. Morris pers. comm.), which are likely to be deposited to the benthic sediments in regions of the North Sea where tiddi currents are low and the thermocline weak. As a high proportion of some organic contaminants (e.g. $96 \%$ of PCBs for the North Sea; Huiskes \& Rozema 1988) are deposited from the atmosphere and bind to particulate organic matter, they may be similarly accumulated.

The workshop data indicate that mechanisms of contaminant transport and reconcentration can lead to their accumulation to biologically detectable concentrations. The mechanisms involved and the contaminants involved require further research with an emphasis on the vertical flux of contaminants and their accumulation at interfaces.

\section{Integration of relevant data}

Interpretation of the results of ecotoxicological data requires the integration of hydrographic and sedimentological data, besides relating the biological responses with the chemical analyses of different phases. We have tried to reflect this imperative by involving a major input of marine chemistry and by inviting experts in other important fields to provide additional information (see Background Papers). The workshop has demonstrated the need for a greater level of integration between the disciplines, to interpret fully the results of environmental toxicology. The importance of observed toxic effects does not rest solely on the intrinsic worth of the biota ecologically or economically, but also upon those geochemical processes in the sea that are biologically mediated. Ecotoxicology sits at the interface between biology and chemistry and does not merely require the provision of chemical data to link to biological data; it requires the active collaboration of chemists and biologists equally committed to interpret- ing the significance of each other's data and to understanding the processes which led to exposure and biological effects. While the interdependence of these disciplines is accepted, the collaboration of hydrographers applying their models (Becker et al. 1992) is necessary to understand the movement of water masses and the plumes of estuaries like the Elbe and Weser with their burden of contaminants. There is recognition now that contaminants in the sea partition to particulate material, and mechanisms by which contaminants are transported, sorted and sometimes reconcentrated are being identified, so there is a new emphasis on the role of mobile sediments as vehicles for contaminants. The workshop data point specifically to the more mobile and reactive organic-rich fine sediment fraction.

\section{GENERAL CONCLUSIONS}

(1) The German Bight transect was contaminated by a wide range of organic and inorganic compounds related at its inshore end to the effluent from the Rivers Elbe and Weser. The drilling site transect showed a gradient of contamination by oil-based drilling mud, although subsequent REMOTS data indicated it was overlain by $2 \mathrm{~cm}$ of clean sand. Chemical data demonstrated gradients of contamination by anthropogenic compounds at both transects.

(2) Many biological techniques at various levels of organisation respond to the changes in contamination. Biological effects were related primarily to the occurrence of contamination at the benthic or sea surface interfaces. For many of the techniques there was coherence between chemical contamination and the biological responses. Others did not relate to the chemical data, or showed no significant response at all.

(3) New data brought together for the workshop demonstrate that dab migrate over considerable distances $(100 \mathrm{~km})$ which must confound some of the biological data, and show that care is required in their interpretation. Despite movements of dab of several kilometres per day, some techniques indicate rapid responses and may reflect the spatial distribution of contaminants, but the distribution of gross pathology frequencies in relation to contaminant gradients may be obscured.

(4) The workshop demonstrated clearly the need for greater collaboration between chemists, biologists and statisticians, together with scientists from other disciplines from the earliest planning stages, because the key question related to the exposure of organisms to toxic contaminants in the environment was between the disciplines represented by different Working Groups within ICES and IOC. In particular, biological 
effects monitoring methods do not replace analytical chemistry in monitoring programmes, rather they complement it.

(5) Some previous work suggests that contaminants bound to the organic-rich fine particle fraction are deposited on the seabed in the central North Sea. Workshop data to some extent corroborate such findings, showing elevated concentrations of some contaminants. Effects were noted in dab at $\operatorname{Stn} 9$, but more research is needed on the form and flux of toxic contaminants in the central North Sea and on the Dogger Bank in particular.

(6) The most important requirement to demonstrate the sequence of events and the levels of contamination capable of causing fish disease is laboratory experiment, supplemented by epidemiological studies in the environment.

(7) The choice of biological effects monitoring methods depends very much on the objective of the monitoring programme. Thus, biochemical measurements usually offer a relatively specific response (to a particular group of pollutants) over a relatively short time scale, which can be used to anticipate the effects of pollution; at the other end of the scale of biological complexity, analysis of community structure offers a retrospective picture of responses to general environmental changes. Viewed from another perspective, adaptive responses such as MFO induction are probably inevitably more sensitive indicators of the effects of pollution than are higher order changes, since the latter would not occur until the capacity for adaptive responses is exceeded.

(8) The biological techniques, tested during the IOC Oslo and Bermuda Workshops and the Bremerhaven Workshop, were effective in detecting significant contamination in the marine environment. Their most appropriate use in monitoring programmes is in a reconnaissance role to provide focus for subsequent chemical monitoring, because of their ability to integrate the combined effects of all the toxic contaminants present in terms that relate to the primary biological criterion for environmental quality.

\section{LITERATURE CITED}

Addison, R. F., Clarke, K. R. (1990). The IOC/GEEP Bermuda Workshop. J. exp. mar. Biol. Ecol. 138: 1-8

Bayne, B. L., Clarke, K. R., Gray, J. S. (1988). Biological effects of pollutants. Results of a practical workshop. Mar. Ecol. Prog. Ser. 46: 1-278

Becker, G. A., Dick, S., Dippner, J. W. (1992). Hydrography of the German Bight. Mar. Ecol. Prog. Ser. 91: 9-18

Bening, J.-C.. Karbe, L., Schupfner, G. (1992). Liquid/solid phase extraction of water samples used for toxicity testing in the German Bight. Mar. Ecol. Prog. Ser. 91: 233-236

Cameron, P., Berg, J. (1992). Morphological and chromosomal aberrations during embryonic development in dab Limanda limanda. Mar. Ecol. Prog. Ser. 91. 163-169

Daan, R., Lewis, W. E., Mulder, M. (1990). Biological effects of discharged oil-contaminated drill cuttings in the North Sea. Boorspueling III-IV, NIOZ-rapport 1990-5. NIOZ, Texel, The Netherlands, $79 \mathrm{pp}$.

Ernst, W., Boon, J. P., Webber, R. (1988). Occurrence and fate of organic micropollutants in the North Sea. In: Salomens, W., Bayne, B. L., Duursma, E. K., Förstner, U. (eds.) Pollution of the North Sea: an assessment. SpringerVerlag, Berlin, p. 284-299

Huiskes, H. H. L., Rozema, J. (1988). The impact of anthropogenic activities on the coastal wetlands of the North Sea. In: Salomens, W., Bayne, B. L., Duursma, E. K., Förstner, U. (eds.) Pollution of the North Sea: an assessment. SpringerVerlag, Berlin, p. 455-473

Moore, M. N. (1992). Molecular and cellular pathology: summary. Mar. Ecol. Prog. Ser. 91: 117-119

Rijnsdorp, A. D., Vethaak, A. D., van Leeuwen, P. I. (1992). Population biology of dab Limanda limanda in the southeastern North Sea. Mar. Ecol. Prog. Ser. 91: 19-35

Rumohr, H., Schomann, H. (1992). REMOTS sediment profiles around an exploratory drilling rig in the southern North Sea. Mar. Ecol. Prog. Ser. 91: 303-311

Stebbing, A. R. D., Dethlefsen, V. (1992). Introduction to the Bremerhaven Workshop on Biological Effects of Contaminants. Mar. Ecol. Prog. Ser. 91: 1-8

Sünderman, J., Degens, E. T (1989). The North Sea: water exchange and pollution of the North Sea. Dingwort, Hamburg

Wilson, D. P., Armstrong, F. A. J. (1961). Biological differences between sea waters: experiments in 1960. J. mar. biol. Ass. U.K. 41. 663-681 